\title{
Qualities of the environment that support a sense of home and belonging in nursing homes for older people
}

\author{
Karin Johansson ${ }^{1}$, Lena Borell ${ }^{1}$ and Lena Rosenberg ${ }^{1 \star}$ (D) \\ ${ }^{1}$ Department of NVS, Division of Occupational Therapy, Karolinska Institutet, Huddinge, Sweden \\ ${ }^{*}$ Corresponding author. Email: lena.rosenberg@ki.se
}

(Accepted 16 June 2020; first published online 17 July 2020)

\begin{abstract}
The aim of this study was to contribute with knowledge about how a sense of home and belonging is enacted and can be supported in everyday life, with a particular focus on the relationships that connect everyday life and the environment in nursing home contexts. The concepts 'a sense of home' and 'belonging' were chosen with the ambition to grasp values grounded in experiences and everyday practices, with an openness for various aspects that can support an enjoyable life and comfort for nursing home residents. The study focused on communal areas, e.g. dining room, kitchen, corridors and gardens, that serve as arenas where nursing home residents' everyday lives expand beyond the private room. Ethnographic methods were applied to identify and explore situations where a sense of home and belonging were enacted in nursing homes that had been acknowledged as good examples of nursing home environments. Through the analytic process, four qualities were identified: (a) a cornerstone for stability and everydayness, (b) the beating heart, (c) spatial dynamics, and (d) magnetic places. Following from the chosen methodology, the findings provide a situated understanding of how communal areas in nursing homes can invite a sense of home and belonging for the residents.
\end{abstract}

Keywords: environment; nursing home; residential care home; sense of home; belonging; dementia; Alzheimer's disease; ethnography

\section{Introduction}

It is well established that the environment, including the architecture, interior design and artefacts, as well as routines and social practices, plays an important role in how everyday life in nursing homes is shaped and experienced (Torrington, 2009; Fleming et al., 2016; Kenkmann et al., 2017; Calkins, 2018; Chaudhury et al., 2018). Still, there is insufficient knowledge that grasps how the environment is enacted and experienced through everyday life in nursing home contexts. Our approach to explore this topic is to learn from 'good examples'

(C) The Author(s), 2020. Published by Cambridge University Press. This is an Open Access article, distributed under the terms of the Creative Commons Attribution-NonCommercial-NoDerivatives licence (http://creativecommons.org/ licenses/by-nc-nd/4.0/), which permits non-commercial re-use, distribution, and reproduction in any medium, provided the original work is unaltered and is properly cited. The written permission of Cambridge University Press must be obtained for commercial re-use or in order to create a derivative work. 
and to inquire into how communal areas in nursing homes can invite actions and experiences associated with 'a sense of home' and belonging among nursing home residents in Sweden.

\section{Background}

Nursing homes are characterised by being simultaneously a care-providing institution and a long-term home for older persons who have difficulties managing everyday life due to their health conditions (Rijnaard et al., 2016). Discussions about nursing home environments often tend to emphasise the dichotomy between homelike and institutional environments, with homelike environments being preferred (Shield et al., 2014; Klaassens and Meijering, 2015; Calkins, 2018). As concluded by Calkins (2009), the term 'non-institutional' is frequently used to denote quality in the design of nursing home settings, based on an implicit assumption that there is an agreement on what the antithesis of institutional means. The general ambition to avoid institutional features in nursing home design is (implicit or explicit) derived from Goffman's (19903) definition of the 'total institution' (Artner, 2018). According to Goffman, residents in a total institution have little control over their lives and their personal identity is threatened. Goffman identified some characteristics of a total institution, including that it is inhabited by likesituated individuals who become cut off from the wider society, a separation between residents and staff, and that all parts of residents' life take place within the institution and is highly regulated by administrative routines. Goffman also concluded that the total institution is manifested through environmental features such as locked doors and enclosed buildings. As discussed by, for example, Artner (2018), there is a lack of research on how the total institution is shaped through the everyday interactions involving material and spatial arrangement and the social actors in nursing home contexts. Reflecting this lack of research, the manifestations of an ambition for a non-institutional design in nursing homes tend to be based on general associations of institutions as, for example, long corridors and visible nursing stations, rather than more in-depth understandings of how characteristics of a total institution are manifested. Homelikeness is often presented as the antithesis of the institution. There is no clear definition of what constitutes homelikeness (Marquardt et al., 2014), but smaller unit size and domesticity are generally recommended as manifestations of homelikeness (Calkins, 2018; Chaudhury et al., 2018). However, homelikeness in relation to nursing homes has been discussed and questioned by several scholars (Fay and Owen, 2012; Falk et al., 2013; Nakrem et al., 2013), who emphasise that the idea of homelikeness tends to be based on stereotyped cultural values about what constitute a home, rather than on what is important for nursing home residents to feel comfortable and to live an enjoyable life. Additionally, this understanding of home tends to be based on romantic perspectives on the home as a place for safety, comfort and positive relationships, overlooking how the home can be an arena for conflict, discomfort and unsafety (Penney, 2013, Hillcoat-Nallétamby and Ogg, 2014). The concepts 'a sense of home' (Falk et al., 2013), 'at homeness' (Cutchin et al., 2003) or, in more everyday language, to feel at home, are used to denote a deep sense of comfort, and have been suggested as alternative goals to guide nursing 
home design (Calkins, 2018). Those concepts are not necessarily connected to the home or dwelling but also, for example, to people, activities or an atmosphere. At-homeness has been defined as 'the usually unnoticed, taken-for-granted situation of being comfortable in and familiar with the everyday world' (Seamon, 1979: 70), and similarly a sense of home has been defined as experiences of belonging and comfort (Rijnaard et al., 2016; Calkins, 2018). As argued by Rijnard et al. (2016), a sense of home can be associated with experiences of knowing 'how to act and behave' at a particular place, which is of central importance in the context of dementia. Sense of home, at-homeness and feeling at home are all experiencebased, which implies that they cannot be attributed to a nursing home without the people and the social practices that constitute the place. Through the focus on situated experiences, these concepts hold a potential to grasp various aspects that contribute to people being able to feel comfortable and have a good and enjoyable life in the specific context of the nursing home (Cutchin et al., 2003; Falk et al., 2013; van Hoof et al., 2015; Rijnaard et al., 2016). In this paper, we use the term 'a sense of home' interchangeably with the overlapping definitions of the terms 'at-homeness' and 'feeling at home'.

Positive relationships to place have in environmental gerontology often been conceptualised as place attachment (Rowles et al., 2003; Johansson et al., 2013; Wiles et al., 2012), while in anthropology and sociology relations to and through place have often been encompassed within the wider concept of 'belonging' (Degnen, 2016). Belonging is conceptualised as relational and includes the social and cultural dynamics that connect place, identity and belonging over time through social practices (Degnen, 2016). In the context of ageing and later life, place attachment and belonging are commonly attributed to long-term relationships with a place, developed over the lifespan (Peace et al., 2005; Rowles and Chaudhury, 2005; Gilleard et al., 2007; Degnen, 2016). However, this understanding does not fully attend to how people continuously negotiate place through social practices over a lifetime (Cutchin, 2003; Johansson et al., 2013). Such negotiations might be particularly crucial in situations of change, such as when there are significant alterations in factors associated with social life or health (Cutchin et al., 2003; Moore and Ekerdt, 2011; Johansson et al., 2013). From this we conclude that belonging and a sense of home can emerge as people create and negotiate place through experiences and everyday practices and relations in nursing home contexts (Gesler and Kearnes, 2002; Huot and Rudman, 2010; Andrews et al., 2013). This means that older nursing home residents' identities, relationships and preferences cannot be understood as static products of their past lives, but rather as continuously changing with their ongoing everyday life (Mondaca et al., 2019).

Nursing homes generally include some communal areas, e.g. dining room, kitchen, corridors and gardens, that serve as arenas where nursing home residents can be part of a community and have an everyday life that expands beyond the private room (Fleming et al., 2016). Therefore, the communal areas might hold qualities associated with a local community, similar to a local café or pub, or a corner or square in the local neighbourhood. In a review, Fleming et al. (2016) concluded that nursing home buildings that provide a variety of private and community spaces and opportunities to participate in different activities are associated with higher quality of life among the residents. Existing research on communal areas in nursing homes 
has, to a large extent, focused on physical and cognitive accessibility for the residents (Day et al., 2000; Calkins, 2009; Robinson et al., 2010; Digby and Bloomer, 2014; Fleming et al., 2016). This research recommends, for example, adequate lighting, informed application of colour contrast in tableware and floors (Marquardt et al., 2014), an open-plan environment in which visual access is favoured (de Boer et al., 2018), wide corridors and wide doorways for easy access for people who use wheelchairs (Fleming et al., 2016) and access to outdoor spaces (Calkins, 2009; Kenkmann et al., 2017). Existing research also provides knowledge concerning how communal areas should be designed in order to meet individual preferences and needs among the residents (Fleming et al., 2016), pointing towards the importance of having access to a garden (Digby and Bloomer, 2014), a place to walk (Robinson et al., 2010) and a connection to a wider society (Day et al., 2000). Although this research provides important knowledge about basic conditions to make the communal areas accessible and attractive for individual residents, it provides little guidance on how those spaces can be places for an everyday life that supports experiences of a sense of home and belonging. As concluded by de Boer et al. (2018), research on how the environment is used by residents is scarce.

In conclusion, very little is known about how communal areas in nursing homes can become places that provide support to enable residents to live an enjoyable everyday life. It is a challenge to conceptualise adequately common-sense values such as comfort and enjoyable life that can be understood to signify the 'wished-for state of the situation' in nursing homes. For this paper, we chose a sense of home and belonging to denote values grounded in experiences and everyday practices, and with an openness for various aspects that can support an enjoyable life and comfort for nursing home residents. Little is known about how a sense of home and belonging is enacted in everyday life and the processes and interactions underlying experiences associated with those values. In particular, there is a lack of knowledge about a sense of home and belonging that grasps the complexity and situatedness that characterises everyday life in relation to the environment. Such knowledge is needed in order to create nursing home environments that support a sense of home and belonging for the residents. The present study responds to this need, with the aim to contribute with new knowledge about how a sense of home and belonging is enacted and can be supported in everyday life, with a particular focus on the relationships that connect everyday life and the environment in nursing home contexts.

\section{Methods}

To meet the research aim, the study was designed to identify and explore situations in communal areas where a sense of home and belonging was enacted, in nursing homes in Sweden that had been acknowledged as good examples of nursing home environments. An ethnographic method was applied with the ambition of grasping the situatedness and complexity of everyday life (Atkinson et al., 2008; Pink, 2009).

\section{Study context-nursing homes in Sweden}

In Sweden, nursing homes with 24-hour staff are offered as an option for persons who can no longer manage everyday life in their ordinary dwelling, based on an 
assessment of persons' needs by municipal street-level bureaucrats. Qualifying as eligible often includes functional limitations associated with dementia diseases and a majority of the nursing homes in Sweden have special dementia units. At present (2019), 11.9 per cent of the population aged 80 or older live in a nursing home (National Board of Health and Welfare, 2019a) and two out of three living in nursing homes are women (National Board of Health and Welfare, 2019b). Since the 1990s, Swedish policies state that people living in a nursing home should be provided with their own private room/apartment including a bathroom and a pantry. The national guidelines for care of persons with a dementia disease (National Board of Health and Welfare, 2017) recommend that the living environment should be small scale, which often takes the form of large buildings that include a number of small units composed of eight or nine apartments and communal areas such as living rooms and dining rooms. Further, the national guidelines state that the environment should be familiar to the residents and invite them to take part in daily activities. The individual apartment is furnished with residents' own furniture and decorations. In Sweden, municipalities have the responsibility for the cost and quality of nursing homes. Nursing homes can be run by private actors and still be financed by the municipality. The private sector accounts for approximately 20 per cent of nursing home services in Sweden, mostly situated in the larger cities (National Board of Health and Welfare, 2019a). Once assessed as eligible for a nursing home room/apartment, the individual can choose a preferred nursing home. However, since the number of nursing homes is limited, the individual cannot always move to the place they prefer.

\section{Included nursing homes}

We assumed that nursing homes that had been acknowledged as good examples of design would provide good conditions for situations where a sense of home and belonging was enacted. We searched for nursing homes in several ways, including general internet searches, public media, professional networks and organisations for people with dementia, to identify nursing homes in Sweden that had been acknowledged as good examples of design. We did not apply any criteria to 'confirm' the quality of the nursing homes. From 30 identified nursing homes, we selected nine, with the ambition of achieving variety in terms of geographic and socio-demographic location, size, organisational form (municipal, private, nonprofit) and explicit profile. To make this selection, we gathered more information about each of the 30 nursing homes on the internet, including information from the nursing homes' official websites and other sources such as local and national newspapers, results from competitions and awards, etc. We contacted the managers of the nine selected nursing homes by email and telephone with an invitation to participate in the study. Two of the invited nursing homes declined to participate. We then contacted one additional nursing home which agreed to participate, resulting in eight included nursing homes. For further information about the included nursing homes, see Table 1. For this article, each nursing home is given a fictive name in English. 


\begin{tabular}{|c|c|c|c|c|}
\hline $\begin{array}{l}\text { Fictive } \\
\text { name of } \mathrm{NH}\end{array}$ & $\begin{array}{l}\text { Organisational } \\
\text { form and size }\end{array}$ & Building and location & Common areas & Characteristics \\
\hline $\begin{array}{l}\text { Apple } \\
\text { Garden }\end{array}$ & $\begin{array}{l}\text { Public } \\
81 \text { apts, mixed } \\
\text { dementia/somatic } \\
\text { units }\end{array}$ & $\begin{array}{l}\text { Purpose-built in } 2013 \text {. Apts } 30 \mathrm{~m}^{2} \text {. } \\
\text { Three floors, two units on each floor. } \\
\text { Small-town location. }\end{array}$ & $\begin{array}{l}\text { Each unit: large combined dining } \\
\text { and living room, smaller living } \\
\text { room. } \\
\text { Whole NH: big garden, one large } \\
\text { common room, smaller rooms for } \\
\text { specific activities (spa, reminicence } \\
\text { room, etc.). }\end{array}$ & $\begin{array}{l}\text { Spacious and modern. Garden with } \\
\text { flower and vegetable beds, } \\
\text { greenhouse, chickens and } \\
\text { sculptures. Explicit focus on activity } \\
\text { and participation for staff and } \\
\text { residents. Closed kitchens at the } \\
\text { units. }\end{array}$ \\
\hline $\begin{array}{l}\text { Chestnut } \\
\text { Manor }\end{array}$ & $\begin{array}{l}\text { Owned and } \\
\text { managed by a } \\
\text { Christian church } \\
54 \text { apts, } 26 \text { in } \\
\text { dementia units }\end{array}$ & $\begin{array}{l}\text { Purpose-built in } 2008 \text {. Apts } 27-35 \mathrm{~m}^{2} \text {. } \\
\text { Three floors, two units on each floor. } \\
\text { Located in the centre of a larger city. }\end{array}$ & $\begin{array}{l}\text { Each unit: living room, open } \\
\text { kitchen/dining room, TV room, } \\
\text { balcony and spacious corridors. } \\
\text { Whole NH: chapel and an enclosed } \\
\text { garden. }\end{array}$ & $\begin{array}{l}\text { Based on Christian (Protestant) } \\
\text { values. Integrated with ordinary apt } \\
\text { buildings, with a shared enclosed } \\
\text { yard. Modern and functional indoor } \\
\text { design in light colours. }\end{array}$ \\
\hline Forest Road & $\begin{array}{l}\text { Public } \\
40 \text { apts, mixed } \\
\text { dementia/somatic } \\
\text { units }\end{array}$ & $\begin{array}{l}\text { Purpose-built in } 2014 \text {. Apts } 32 \mathrm{~m}^{2} \text {. } \\
\text { Two floors, two units on each floor. } \\
\text { Rural location. }\end{array}$ & $\begin{array}{l}\text { Each unit: dining room, spacious } \\
\text { multi-functional living room. } \\
\text { Whole NH: Large winter garden } \\
\text { with walking paths, a stage and } \\
\text { sitting areas. Garden under } \\
\text { construction. }\end{array}$ & $\begin{array}{l}\text { Large winter garden with direct } \\
\text { access from bottom floor and a long } \\
\text { balcony on upper floor (looking } \\
\text { down on the winter garden). Modern } \\
\text { functional furniture and interior } \\
\text { design. Closed kitchens at the units. }\end{array}$ \\
\hline Lime Park & $\begin{array}{l}\text { Public } \\
36 \text { apts, } 15 \text { in } \\
\text { dementia units }\end{array}$ & $\begin{array}{l}\text { Purpose-built in } 1992 \text {. Two-room } \\
\text { apts } 42-60 \mathrm{~m}^{2} \text {. Two floors, two units } \\
\text { on each floor. Located in a detached } \\
\text { suburban area. }\end{array}$ & $\begin{array}{l}\text { Each unit: living room, open } \\
\text { kitchen/dining room. } \\
\text { Whole NH: Large common room, } \\
\text { garden/park. }\end{array}$ & $\begin{array}{l}\text { Large room for common activities } \\
\text { on bottom floor. Open doors with } \\
\text { access to a large garden/park with } \\
\text { fruit trees, walking paths and } \\
\text { several sitting areas. }\end{array}$ \\
\hline Oak Palace & $\begin{array}{l}\text { Managed by a } \\
\text { private company } \\
33 \text { apts, } 33 \text { in } \\
\text { dementia units }\end{array}$ & $\begin{array}{l}\text { Built in } 1913 \text {, renovated in } 1996 . \text { Apts } \\
>30 \mathrm{~m}^{2} . \text { Three floors, one unit on } \\
\text { each floor. Located in the city centre } \\
\text { of a larger city. }\end{array}$ & $\begin{array}{l}\text { Each floor: living room, open } \\
\text { kitchen/dining room, a smaller } \\
\text { dining room and spacious } \\
\text { corridors. } \\
\text { Whole NH: Small garden } \\
\text { connected to a hospital park. }\end{array}$ & $\begin{array}{l}\text { Profiled towards music and crafts. } \\
\text { Original furniture and indoor } \\
\text { decorations from the early } 1900 \text { s } \\
\text { when the NH was founded } \\
\text { combined with new furniture in } \\
\text { matching style. Light colours, big } \\
\text { windows, high ceilings. }\end{array}$ \\
\hline
\end{tabular}




\begin{tabular}{|c|c|c|c|c|}
\hline $\begin{array}{l}\text { Olive Tree } \\
\text { Path }\end{array}$ & $\begin{array}{l}\text { Private non-profit } \\
\text { organisation } \\
31 \text { apts, not } \\
\text { divided into clear } \\
\text { units }\end{array}$ & $\begin{array}{l}\text { History from } 1853 \text { in a building } \\
\text { located in the city centre. In present } \\
\text { building since } 1988 \text {. Four floors. } \\
\text { Suburban location in a larger city. }\end{array}$ & $\begin{array}{l}\text { Each floor: Smaller common areas } \\
\text { used differently on each floor } \\
\text { (library, seating area, etc.). Whole } \\
\mathrm{NH} \text { : large living room that can be } \\
\text { divided into two rooms, dining } \\
\text { room, chapel and garden. }\end{array}$ & $\begin{array}{l}\text { Catholic profile. The chapel is a } \\
\text { meeting place that attracts people } \\
\text { outside the NH. Catholics from all } \\
\text { over the world live and work at the } \\
\mathrm{NH} \text {. A few nuns and a Catholic priest } \\
\text { live in the building and take part in } \\
\text { the daily work. Indoor design in } \\
\text { antique bourgeois style with } \\
\text { oriental carpets, dark wood } \\
\text { furniture and old paintings. }\end{array}$ \\
\hline Rowan Hill & $\begin{array}{l}\text { Public } \\
96 \text { apts, } 32 \text { in } \\
\text { dementia units }\end{array}$ & $\begin{array}{l}\text { Rebuilt in } 1999 \text { from an ordinary apt } \\
\text { building. Renovated in } 2012 \text {. Apts } 30 \\
\mathrm{~m}^{2} \text {. Three floors, two units on each } \\
\text { floor. Located in a suburban area. }\end{array}$ & $\begin{array}{l}\text { Each unit ( } 16 \text { persons): living } \\
\text { room, small kitchen, dining room, } \\
\text { large built-in balcony. } \\
\text { Whole } \mathrm{NH} \text { : large common room } \\
\text { with kitchen and a bar. Spa, } \\
\text { hairdresser, hobby room and a } \\
\text { garden. }\end{array}$ & $\begin{array}{l}\text { Entry floor that opens up the } \\
\text { nursing home to the outside } \\
\text { community. Colourful and } \\
\text { decorative indoor design. Explicitly } \\
\text { striving towards 'non-institutional' } \\
\text { environment (e.g. tufted carpets, } \\
\text { staff wear private clothes). Staff and } \\
\text { residents have influence over choice } \\
\text { of furniture and decorations. }\end{array}$ \\
\hline $\begin{array}{l}\text { Villa } \\
\text { Hazelwood }\end{array}$ & $\begin{array}{l}\text { Private non-profit } \\
\text { organisation } \\
8 \text { apts in one } \\
\text { dementia unit }\end{array}$ & $\begin{array}{l}\text { Expanded from an ordinary family } \\
\text { house. Two floors, NH located on the } \\
\text { bottom floor. On the upper floor apts } \\
\text { for independent-living seniors. Small } \\
\text { town/rural location. }\end{array}$ & $\begin{array}{l}\text { Whole NH: large country-style } \\
\text { kitchen, dining room, living room, } \\
\text { garden. }\end{array}$ & $\begin{array}{l}\text { Anthroposophical approach and } \\
\text { small scale. Many features } \\
\text { associated with rural family house, } \\
\text { including a cat and a hat rack by the } \\
\text { entrance. Anthroposophical design } \\
\text { with wooden floors and wall panels, } \\
\text { soft colours and hand-painted signs. }\end{array}$ \\
\hline
\end{tabular}

Notes: apt: apartment. $\mathrm{m}^{2}$ : square metres. 


\section{Data generation and analysis}

To be able to grasp the complexity that shapes everyday situations at nursing homes, the ethnographic method included interviews, participant observations, photographing and observations of the environment (Atkinson et al., 2008), combined with iterative reflective and analytic discussion among the researchers. Three researchers, including two of the authors (KJ and LR), who all have experience from research and work in nursing homes, engaged with residents, staff and visiting kin in everyday situations for two days (about six hours per day) at each setting, resulting in about 200 hours of observations. When contacting the managers to organise the visit, we emphasised that we were interested in the ordinary everyday life and therefore asked them not to adjust anything for our visit. Each visit started with a 30-90-minute open interview with the manager, focusing on core values guiding the practice, the history of the nursing home and facts about, for example, activities, mealtime situations, etc. At some sites the manager invited additional staff members to the interview. These individuals were identified by the manager as holding positions and/or competence of relevance for the research project. The interview was in all cases spontaneously followed by a tour of the whole or parts of the nursing home, guided by the manager. This tour provided us with opportunities to ask further questions about things that had been mentioned in the interview, and also served to introduce us to the staff. After the tour, the three researchers moved freely around in the nursing home, with a few restrictions set by the managers to protect vulnerable residents from potential disturbance. Duration and level of participation in different situations was decided in the moment, with consideration to what was going on and to the residents' and staff's reactions (Atkinson et al., 2008; Rosenberg and Johansson, 2012).

We conducted participant observations in order to provide possibilities for us to learn to see, hear, smell and be involved with everyday practices that made sense in relation to belonging and a sense of home (Ingold, 2008; Pink, 2009). We particularly stayed with situations where we identified that experiences of belonging and a sense of home were manifested among the residents. To do this, we trusted in our own experiences of the ambience and in our interpretations of verbal and emotional expressions and social interactions among the residents. Our experiences from nursing home contexts served as a tool in this process to identify situations that stand out from how everyday life is commonly shaped in nursing home contexts in Sweden, but that from a common-sense perspective might appear natural and self-evident. This included, for example, situations in which a resident was resting on a sofa in a communal room or when a resident invited the researchers for coffee in the shared kitchen.

Given the specific challenges of communicating with persons with a dementia disease, we were especially sensitive to the residents' different ways of expressing their experiences. We brought our experiences and reflections of the immediate situation into dialogues with people present in the situation, including, for example, residents, staff and visiting kin (Pink, 2009). As tools in this dialogue we took photographs, using digital tablets, with nursing home residents to capture spots and artefacts they liked or found interesting for other reasons, in situations where we judged this to be appropriate and relevant. The digital tablets made it 
possible to look at, and talk about, the photographs immediately. Additionally, we took photographs of situations, places and artefacts that appeared to be relevant for generating experiences of a sense of home and belonging, and to document the places generally. To respect the privacy of the residents, faces of residents were not included in the photographs.

As part of the analytic process, the three researchers who had visited the nursing homes repeatedly met to reflect upon our experiences and interactions with residents, staff and other people present at the site, and to connect those to the research aim. Those meetings took place on site as well as after the site visits. As data generation proceeded, data and reflection from previous site visits served to sensitise us to aspects and situations that might be of importance to understanding how communal areas in nursing homes can support belonging and a sense of home. Further, it served to enable comparisons, giving rise to analytical questions such as: what is the difference between a situation that seems to generate belonging or a sense of home and one that does not, when they share many similarities? Participant observations and reflective discussions were documented through extensive field notes.

When we had finished the site visits, we integrated all data, including field notes, photographs and notes from reflective discussions, in a hermeneutic process (Ricoeur, 1991; Gustavsson, 2000) to enquire into how communal areas in nursing homes can support experiences of a sense of home and belonging for nursing home residents. All authors were involved in this phase of the analysis. In this process we used photographs taken at the site visits to illustrate and reflect further upon how belonging and a sense of home were manifested and enacted and how this was facilitated.

\section{Ethical considerations}

To conduct research in settings where people live and work comes with several ethical challenges. This is particularly salient in nursing home settings where many of the residents have dementia and where many of the residents can be seen as being in a vulnerable situation. To avoid harm and disturbance we took careful actions based on advice from staff and our own judgements. We carefully explained why we were there each time we encountered staff, residents or significant others, or when someone raised questions about our presence. We were sensitive to signals showing that residents were uncomfortable with us being there and withdrew from such situations. When participating in activities that took place during site visits, we noticed atmospheres and reactions to our presence and adjusted our actions in response to that. In agreement with the managers, photographs were taken in a way that residents should not be recognised. Further, we were sensitive to whether people present were comfortable with us taking photographs. In the findings, residents, staff and nursing homes are given fictive names to ensure their privacy and anonymity.

The Stockholm Regional Ethic Committee gave ethical approval for the study (2015/512-31/5).

\section{Findings}

Through the analysis we identified four qualities of communal areas that supported the enactment of sense of home and belonging: (a) a cornerstone for stability and 
everydayness, (b) the beating heart, (c) spatial dynamics, and (d) magnetic places. In the following we present the four qualities in more detail. These qualities occurred separately as well as simultaneously in different situations during the site visits.

\section{A cornerstone for stability and everydayness}

Our attention to the quality of 'a cornerstone for stability and everydayness' was initiated by the different ways that residents communicated appreciation and relief that everyday duties such as maintenance of the house and household were not their responsibility in the setting. For example, one woman at Lime Park said: 'We get very good food here and the girls are so nice. They take care of everything one could wish for.'

The residents often communicated this in connection with the visual presence of staff, the smell from or visual appearance of cooking, or the view of a clean tablecloth. Additionally, the nursing home residents commonly pointed out things like fresh flowers in a vase or a shiny, well-cleaned floor as spots and artefacts they liked when we took photographs together. We understood such sources of sensory impressions to be serving as familiar signs indicating that food would be served or that the premises were being kept nice and clean, i.e. that the residents could rely on staff to care for the premises, including physical features, as well as the residents. Overall, we understood the cornerstone for stability and everydayness to allow for spontaneous as well as planned actions and events to take place without putting the residents at risk of emotional and/or social distress. We found that the cornerstone of stability and everydayness could be generated through everyday routines, and through the staff's way of safeguarding situations that could potentially be stressful for residents.

This can be exemplified by a situation at Oak Palace. One of the staff members was cleaning up after breakfast, when a man, Stig, came into the kitchen. Stig moved around in a restless way and it seemed as if he did not know what to do, which the researcher interpreted as Stig being worried and anxious. The staff was about to tie up a bin bag, and asked Stig if he could take out the rubbish. Stig took the bin bag in a way that showed that this was something he knew how to do. Since the rubbish bin was outside the entrance to the unit, the staff had to go with him. In this example, the staff made use of the situation and invited Stig to do an everyday household chore together with her, which Stig in this case seemed to appreciate. This was facilitated by an open kitchen design which socially as well physically connected residents with the household maintenance. This allowed Stig to perform and participate in an authentic household activity with retained dignity, without having to bear the full responsibility for it being done.

The staff could also arrange the communal areas to enable the residents to be involved in everyday matters and social interactions without the immediate involvement of staff. This can be exemplified by a situation when a resident, Olof, residing at a unit for persons with a dementia disease, offered coffee and cake to one of the researchers in the communal kitchen at Rowan Hill, described in this excerpt:

I stand in the kitchen with Olof. I have heard [from staff] that he usually helps in the kitchen. I notice that he seems to be comfortable being in the kitchen. There is 
a quarter part of a cake on the bench in front of the window and he asks me if I want a piece. It seems like he feels a co-ownership of the kitchen and that is shown when he offers me the cake ... Seeing Olof in the kitchen, looking out through the window and commenting on the weather gives me a sense of home. The everydayness in the situation feels nice. There are no staff monitoring the kitchen or worrying about the residents being there. The attitude is that the kitchen is the residents' living space and that the staff only work there. (Field notes from Rowan Hill)

We understood that in the example, Olof felt confident that this was a place where he could be the host for a visiting guest. In this case, the staff had an explicit ambition to invite the residents to feel 'at home' and consciously made fruits, coffee and cakes available to the residents in the kitchen. To ensure that the residents can use the kitchen safely by themselves, the staff hide objects that could cause potential danger. The attitude that the kitchen is the residents' living space was explicitly told to us by the staff. This also reflected the ideology that the residents should have ownership of the place communicated by the manager at Rowan Hill.

In summary, the cornerstone for stability and everydayness can be understood as an expression of care and safety that provides a basis for participation and agency in everyday life among nursing home residents. This supports a sense of home and belonging as residents' engagement in everyday activities was not threatened by their limited capabilities to manage everyday life situations on their own.

\section{The beating heart}

Throughout the site visits we were struck by how both residents and staff showed confidence and pride in being part of that particular nursing home. We elaborated upon this finding in light of the specific words one staff member at Olive Tree Path and one manager at Rowan Hill used to describe the character and the shared culture of their respective nursing homes. They both explained how one particular area in the nursing home served as the centre where the culture of the nursing home was present in an intense form, serving as 'the heart of the nursing home'. In line with the heart metaphor, the culture permeated outward to be manifested in less-intense ways throughout the nursing home. The specific culture was expressed through actions among residents and staff, as well as through details such as decorations and furniture.

In the nursing homes where we identified this quality, one important aspect of 'the beating heart' was that the shared culture was connected to the wider society, either by being connected to a specific community, such as a religious community or a local community, or by inviting the society outside the nursing home to be part of the nursing home culture.

At Olive Tree Path, which had an explicit core value grounded in Catholicism, one of the staff told us that 'the chapel is the heart of the nursing home', explaining that it is like a tabernacle where Jesus is present, and from there spreads through the whole nursing home'. Through the analysis, we identified that the chapel together with the daily presence of nuns and a priest and artefacts with religious meaning tuned in with the residents' faith and served to support experiences and actions associated with a specific shared faith. Further, the history of the origin of the nursing home strengthened this shared culture, as described in the following excerpt: 
The managers told about the history of the nursing home which originated in the mid-nineteenth century. It was funded by a Swedish queen who supported Catholicism in a time when Catholics were diminishing and disrespected. Originally it was a home for poor and old Catholics. During the two days of site visit at Olive Tree Path we realised that this story was very vivid throughout the nursing home. It was told or referred to numerous times by staff and residents, often in relationship to portraits of the queen that were present at several places. (Field notes from Olive Tree Path)

Additionally, the culture and core values within the Catholic nursing home were connected to a larger international, national and local Catholic community. This enabled the residents of the Catholic nursing home to experience belonging to an authentic community that expanded beyond the nursing home.

The connection between the culture that characterised the nursing home and the larger society was evident in another way at Forest Road. This nursing home was situated in a rural community, and we identified that the nursing home was part of the local community in a very vivid way, and that this grounding in the local community characterised the culture shared by the residents, staff and visitors. The nursing home was also a matter of concern to different actors in the local community, which could, for example, be seen in that artworks, furniture and various products used as lottery prizes were donated by individuals and organisations from the local community and that the local newspaper included articles about the nursing home. Additionally, staff as well as residents and visiting kin referred to both historical and present-day persons and events in the local community in their everyday conversations and actions. Thus, 'the beating heart' supported a continuous belonging and participation in the local community for the nursing home residents.

In the examples described above, the society outside the nursing home was invited to share and be part of the culture of the nursing home. This was apparent in that 'the heart' was easily accessible through its location. Further, it was socially accessible through the arrangement of activities that actively welcomed a wider population in addition to the nursing home residents and their relatives. Most importantly, the culture of the nursing homes held a value that served as a resource for a community that expanded beyond the nursing home itself.

'The beating heart' refers to a specific place, physical and/or symbolic, that serves as a core or a centre for the explicit or implicit shared culture that was present throughout the nursing home. This shared culture supported a sense of home and belonging by generating a pride in being part of the nursing home, and a familiarity in the sense of knowing 'how we do it here'. Importantly, this culture was connected to a wider society outside the nursing home and not isolated within the specific nursing home.

\section{Spatial dynamics}

During the field visits we identified a number of situations where the communal areas in the nursing homes were used in dynamic ways to meet changing individual, as well as collective, needs. Staff actively made use of the existing inherent 
possibilities in the environment in response to, for example, shifts in mood among residents or atmosphere in a situation. Such dynamics could take the form of, for example, tailoring the room for different group sizes and for different activities or purposefully choosing a space for a specific activity. We understood 'spatial dynamics' to support belonging and a sense of home by providing possibilities for variations on a small-scale everyday basis. This was facilitated by an interior layout that made it easy, physically as well as socially, to move between different spaces, in combination with routines and attitudes among staff that allowed for flexibility. We took part in various situations in which 'spatial dynamics' were manifested through the staff's way of responding to emotional distress among residents. By guiding residents to another space and another activity, staff facilitated a shift in the situation from being stressful towards being peaceful and joyful. This can be illustrated by a situation at Villa Hazelwood described in this excerpt:

I walk into the kitchen and sit down at the big pine table where three people are still sitting after breakfast. Two residents, Henry and Emelie, sit in the seats closest to the window opposite each other. They do not communicate noticeably. Henry picks photographs in and out of a small box and Emelie browses a local newspaper. Emelie has a coffee cup of an older model in front of her ... I talk to her about what she thinks about the place [the nursing home]. She says 'it's awful, you're trapped, it's like a prison. There are only hills all around this house, so you can't go out'. Emelie says that she wants to go home to Västerbotten [a county about 60 Swedish miles north of the nursing home] where she lives. She seems sad and distressed and one of the staff seems to catch this and soon approaches her with a book of folk tales and asks 'don't you think that it is time to read something? I think there are several people who want to listen to you'. Emelie's mood changes instantly. She seems to want to get started right away. She rises and they [Emelie and staff] decide together that she should read in the living room and the staff say that they should pick up [names] who surely want to join in and listen. Emelie and I sit down on the sofa in the living room and other people who want to listen arrive; three residents, one staff and me. The staff closes the doors to the kitchen and to the hall to keep it calm. The room changes character and ceases to be a transit room. Emelie reads and everyone sits and listens. The reading goes on for a long time, she reads the whole folk tale with continued commitment. The ambience around the sofa became charged with intense and positive overtones. (Field notes from Villa Hazelwood)

We were later informed that Emelie did read for the other residents now and then. The staff helped to gather people for this event, and some of the residents were eager to hear Emelie reading. When people, including one of the staff, were gathered around the sofa the staff closed the door to the kitchen. By doing this, the living room changed from being a room where people and activities could pass through, to being very focused on the reading and listening activity. Emelie's mood changed considerably when she, in a self-confident manner, read from the book. 
Two of the visited nursing homes (Chestnut Manor and Oak Palace) had corridors that included widened spaces that were furnished to create a small room or inviting corner. We took part in some situations that arose in which small-scale variations were created through the use of those spaces for short and intense planned or spontaneous activities. For example, at Chestnut Manor a piano and some armchairs were placed in such a corner in the corridor. One of the residents, Sofia, spontaneously started to play the piano. We were later informed that she had been a professional musician. Other residents soon gathered around the piano and appeared to enjoy the music. We experienced that the situation held a strong positive ambience. After about 15 minutes Sofia stopped playing. The people who had been listening moved away one after another and the social and emotional intensity that characterised the piano sessions faded away, giving space for individual residents to carry on at their own pace.

We noticed that during such intense situations, a few of the residents sat by themselves at some distance from the people gathered around an activity. In this way they could participate with lower intensity in a situation of high intensity. We encountered this phenomenon of distant participation in a number of the nursing homes. For example, at Forest Road, organised activities such as bingo or celebrations took place in an enclosed garden around which the two-storey building was built. Residents also went spontaneously to the garden for a walk, to sit on a bench or for a chat. Some residents chose to sit on benches that were placed in exterior corridors on the second floor facing the indoor garden rather than go to the garden. From there they could participate in a distant and less-intense way, which they expressed through commenting on what was happening and interacting with what was going on in the garden by waving or nodding hello to people. In this way, the garden and the exterior corridors hold the same qualities as a neighbourhood where brief as well as more extensive social interactions take place. Importantly, the 'neighbourhood quality' did not stem from being as if it was a neighbourhood, but rather from being an authentic neighbourhood yet one that was adjusted for people with cognitive and other limitations by being a clearly defined space that is small scale and easily accessible.

As illustrated in the examples, 'spatial dynamics' were found to be constituted by a sensitivity among staff for shifts in interactions, emotional state and actions among the residents. Additionally, 'spatial dynamics' were facilitated by a physical as well as a social flexibility to adjust the situation, with respect to both activity and place in accordance with those shifts.

\section{Magnetic places}

Through the participant observations we identified that there were certain spots within the nursing homes where the residents spent time spontaneously without guidance from the staff. Using magnetism as a metaphor, we labelled those places 'magnetic places' since they seemed to hold an attractive power. The 'magnetism' of those places was sometimes a surprise to us since they could hold qualities that generally are not regarded as attractive such as, for example, lacking decorations or furniture. The analysis showed that the attractive power of such places stemmed from the fact that they carried an inherent potential for spontaneous social interactions 
with other people and activities present at the nursing home, or for connections to the surroundings. As such, those places could support experiences of a sense of home and belonging. The quality 'magnetic places' was not dependent on the immediate involvement of the staff, and therefore it could also be understood to support ownership and control of the situation for the residents.

One example of 'magnetic places' was the entrances at each unit at Lime Park, which included comfortable sitting possibilities. People entering the units, either through stairs or lifts, had to pass the entrance. Further, the postboxes were placed there, giving the residents a reason to stop by. In this way, the entrances could be understood as 'places where things happen'. This did not necessarily include active social interaction. We understood the attractiveness of this place to be due in part to its potentiality for social meetings with other people but also because it is a place which holds the social allowance for being present without taking action or interacting with others.

Other 'magnetic places' hold a potentiality for connection to the surrounding society, as illustrated in this excerpt from field notes from Oak Palace. Oak Palace was a four-storey building where each floor constituted one unit with more or less the same room distribution design. All units included a smaller room located a bit off from the combined kitchen and dining room where residents and staff spend most of their time, in the field notes called 'the solemnity room':

I went to the solemnity room where Jeanette [one resident] just went. She is looking out through the window. It strikes me that the view of the highly trafficked street and the hospital seems to be valued by the residents. I have seen other residents, also on other units who have chosen to stay at this window. Jeanette and I talk about the view. She says that she often looks at the view from this window. Across the street we see a flower bed with violet flowers and Jeanette comments that she finds them beautiful. (Field notes from Oak Palace)

To see the street one had to get close to the window, and there were no sitting possibilities by the window. Still, the residents went there and stayed quite a while, standing or sitting in a wheelchair.

The 'magnetic places' that hold potentiality for connection to the surrounding society were all placed so that there was a sensory permeability to the surroundings. This permeability was often visual, providing a view of places of significance for life outside the nursing home, e.g. a supermarket or a central place for social services such as transportation and health care. In another case the permeability was audial, in the form of sound from the neighbouring music university coming in through open windows.

Overall, 'magnetic places' carried an inherent potential for social interactions with people and activities at the nursing home or its surroundings, even if this potential was not necessarily transformed into actions. In contrast to the other three identified qualities, 'magnetic places' did not include involvement of staff.

\section{Discussion}

The four qualities presented in the findings encompass situated understandings of how communal areas in nursing homes can invite a sense of home and belonging 
for the residents. Overall, the findings in the study suggest that the focus in the design of nursing home settings, and especially the communal areas, should be on identifying the qualities that are of central importance for the 'wished-for state of the situation', rather than on isolated aspects of the environment such as lighting, colour contrast (Marquardt et al., 2014), physical accessibility (Fleming et al., 2016) and access to outdoor spaces (Calkins, 2009). Such aspects might be important components, or even basic prerequisites, to achieve 'wished-for states of the situation' (Calkins, 2009; Fleming et al., 2016; Marquardt et al., 2014), but to support experience-based values such as belonging and a sense of home, such aspects need to be understood as interconnected with the environment that is used in everyday situations at the nursing home (de Boer et al., 2018). The qualities identified in this study can serve as guidance in this process. In line with theories on affordance (Pucillo and Cascini, 2014), the findings from this study should be seen to provide knowledge on how communal areas in nursing homes can invite actions and experiences associated with a sense of home and belonging. From this it follows that the findings cannot be read as instructions on how to design a good nursing home, but rather as suggestions for qualities to strive for when designing both new and existing nursing homes. We suggest that the qualities should not be understood as isolated from each other, or from other potential qualities that were not identified through the methodology applied in this study. Still, each of the qualities is of value in itself, and in the following we discuss the four qualities in relation to existing research.

The quality 'a cornerstone of stability and everydayness' highlighted the positive role of care and safety in supporting a sense of home and belonging for nursing home residents. The provision of care and safety is often associated with institutional aspects, and it is generally argued that such aspects should be hidden to prevent an institutional atmosphere (Shield et al., 2014; Klaassens and Meijering, 2015; Calkins, 2018). As shown by, for example, Parker et al. (2004) and Torrington (2009), high levels of safety in nursing homes often correlate with low levels of enjoyment of activities, environmental control and quality of life among residents. Such findings might stem from a medical focus on safety in nursing home practices which results in a high priority on preventing nursing home residents from doing activities that might harm them, such as leaving the nursing home building on their own or moving about freely and risking a fall. The findings of this study indicate that when care and safety are conducted in a way that gives residents the possibility to initiate and take part in everyday matters on their own, without worrying about failing, (Calkins, 2018), those aspects contribute to experiences of a sense of home and belonging. This finding adds some nuances to existing knowledge about negative consequences of dominating institutional aspects (Fleming et al., 2016). A cornerstone of stability and everydayness, which can be associated with institutional aspects, could support residents' experiences of knowing 'how to act and behave' at a particular place, which is associated with a sense of home (Rijnaard et al., 2016). According to Goffman (1990), the separation between staff and residents and the taking-over of responsibility for residents' basic everyday needs by staff are signifying for the total institution and contribute to residents becoming de-personalised. Thus, the involvement of staff and residents together in everyday duties was shown to be a way to avoid central characteristics of the total institution. 
The characteristics of 'the beating heart' highlighted how a shared and consistent culture and associated values invite experiences of belonging and a sense of home. Similarly, Killett et al. (2016) identified that a sense of community that involves residents as well as staff, visitors, relatives and management supported reciprocal relationships. The findings from our study highlighted the importance of the shared culture being present through the physical environment as well as through routines and social interactions. This supports the conclusion by Killett et al. that

a particular organisational culture in care homes cannot be achieved simply by importing a set of organisational values or a strong leader or the 'right' staff. Rather, it is necessary to find ways of resolving the everyday demands of practice in ways that are consistent with espoused values. (Killett et al., 2016: 185)

The findings from the present study show that 'the beating heart' supported a sense of pride in belonging to the specific nursing home among residents as well as staff, which connects the nursing home to the wider society as a resource. This is mirrored by Killett et al. (2016), who identified that nursing homes that had a strong internal culture had a strong connection to the surrounding society. Research on nursing homes and environment generally agree that a connection to the general society plays an important role in supporting belonging and a sense of home (Calkins, 2018; Day et al., 2000; Parker et al., 2004), and social involvement through activities with people outside the close family have been shown to be important for nursing home residents to develop at-homeness at the nursing home (Cutchin, 2003; Calkins, 2018).

The findings from the present study illustrate how the shared culture at the nursing home was integrated with a wider society and was of concern for a community that expands beyond the nursing home. Nursing homes thereby serve as a social and cultural resource for the wider society, which is an aspect that has not been recognised in previous research. Further, Goffman (1990) argues that the total institution places a barrier between the residents and the wider world. The findings from this study point to how such barriers can be avoided through the quality of 'the beating heart', i.e. through the manifestation of a culture that connects the nursing home with a wider community.

Previous research has pointed to the importance of individual nursing home residents having the possibility for variation in terms of access to a variety of activities and to an outdoor environment (Fleming et al., 2016). The identified characteristic of 'spatial dynamics' adds to this knowledge an understanding of the importance of small-scale variations, in terms of social and emotional intensity, as well as in physical space. The findings provided some examples and suggestions about how such variations can be supported, e.g. through a spatial design that makes it easy to move between rooms or parts of rooms. The skills among staff in being able to create small-scale variations in response to residents' emotions, actions and interactions were shown to be a crucial aspect of 'spatial dynamics'. This is in line with de Boer et al. (2018), who showed that whether potentially beneficial spaces, e.g. outdoor spaces, were used was to a large extent dependent on actions and attitudes among nursing home staff. From this we conclude that identifying whether specific environmental quality indicators are present is not enough 
to understand and assess nursing home quality. Rather, the focus needs to be on how aspects of the environment are integrated in the enactment of everyday life.

It is interesting to note that the possibility to enjoy an activity at some distance was found to be an important aspect to support a sense of home and belonging. This resembles previous research that has pointed towards 'being in place' (Rowles, 1991) or 'being in the atmosphere of doing' (Van't Leven and Jonsson, 2002) as important values in old age. The findings from the present study suggest that the spatial design needed to hold physical possibilities in combination with an attitude among staff and management that respect residents' wishes for distant participation, i.e. being in place or in the atmosphere of doing.

The quality 'magnetic places' was unique compared to the other three identified qualities in that it did not involve direct actions from the staff. Still, it is possible that staff can enhance the potential attractive power of certain places. We have not found similar aspects in literature on the nursing home environment, and in this sense the finding 'magnetic places' provides an important contribution to both practice and scientific knowledge that needs to be explored further in future research.

\section{Methodological considerations}

The methods applied in this study were based on identifying situations where a sense of home and belonging were manifested. Following from this, we do not claim the four identified qualities provide a comprehensive picture of qualities that are relevant to support a sense of home and belonging in nursing home contexts. The four qualities stem from the specific nursing homes that were included in the study, and from the specific situations that we took part in as part of the methodology. Nevertheless, the four qualities contribute valuable scientific knowledge that can serve as guidance for nursing home design.

With the applied method, the analysis is based on 'snapshots' from the eight nursing homes where the site visits were conducted. In line with the ambition concerning the chosen methodology, this generated data from immediate everyday situations. However, this method does not grasp more long-term and continuous aspects of relevance for how a sense of home and belonging is enacted and can be supported in everyday life, e.g. the development of relationships among residents and between residents and staff, and both short-term and long-term life histories of the individual residents. Further, with the methodological focus on situations where a sense of home and belonging were manifested, it follows that only 'good' situations are presented in the findings. During the field visits we encountered situations where no signs of experiences of a sense of home and belonging were manifested and even situations where residents were treated with disrespect. With this said, we want to emphasise that the chosen method cannot identify 'good' nursing homes. Still, we argue that if elements of the identified qualities are present throughout the everyday life at the nursing home, there are possibilities for the nursing home as a whole to support experiences of a sense of home and belonging as part of their continuous everyday life. The study was conducted in Sweden and the findings are to a large extent shaped by this socio-cultural context, which must be considered when the findings are discussed or applied in relation to international contexts. 
Further methodological considerations are the strength as well as the weakness of applying a method where the researchers rely on their own experiences and interpretations of a situation. For example, it needs to be considered how our experiences and interpretations relate to nursing home residents' experiences of a situation. As pointed out by various researchers, shared experience does not mean sameness and the researcher cannot get into other people's bodies to share their experiences (Desjarlais, 2003; Downey, 2005; Pink, 2009). In line with Okely (1994: 47), the chosen method created situations where we together with research participants 'creatively constructed correspondences between experiences', which were further elaborated upon in the analytic process, generating grounded and situated findings.

\section{General conclusions}

The four identified qualities were all anchored in the ongoing everyday life at the nursing home and supported the residents as actors in their everyday lives as part of a community. This enabled belonging and a sense of home to emerge as nursing home residents, staff and other actors created and negotiated place through everyday experiences, practices and relations (Gesler and Kearnes, 2002; Cutchin, 2003; Huot and Rudman, 2010; Andrews et al., 2013; Degnen, 2016; Kenkmann et al., 2017). This can be seen in dialogue with the often-promoted ideology and method of reminiscence, grounded in the understanding of older people as products of their past lives, rather than as living subjects (Mondaca et al., 2018, 2019).

The findings from this study illustrate how staff invited residents to be involved in everyday duties and to be a recourse for the shared everyday life at the nursing home. This aligns with findings from other studies that highlight the importance of staff and residents connecting in everyday situations (Lee et al., 2016; Mondaca et al., 2018). Overall, the present study contributes to the discussion on the dilemma between nursing homes as home and institution by adding nuances to the understanding of how inhabiting as well as supporting aspects of the institution are enacted. Findings from the present study highlight how a total institution (Goffman, 1990) can be avoided in this inherently institutional setting. This points to the importance of nursing home design that is grounded in in-depth understandings of how a total institution is generated and manifested, rather than non-reflected negative associations with any aspect that can be seen as a manifestation of the institution. Following from the chosen methodology, the findings from the present study provide situated understandings of how communal areas in nursing homes can invite a sense of home and belonging for the residents. The four qualities identified in this study, (a) a cornerstone for stability and everydayness, (b) the beating heart, (c) spatial dynamics, and (d) magnetic places, give some insights into how good and enjoyable everyday life for nursing home residents can be supported. These insights are of relevance for practice as well as for theory development about the relationships that connect everyday life and the environment in nursing home contexts.

Acknowledgements. We would like to thank residents, staff and managers at the included nursing homes, who generously invited us to share their everyday situations with them. We would also like to thank Jenny Hjalmarsson for her valuable contribution to data collection and analysis. 
Author contributions. KJ contributed to the conception and design of the study, data collection, analysis and interpretation of data, and the process of writing and revising the manuscript. LB contributed to the conception and design of the study, interpretation of data and revising the manuscript critically for important intellectual content. LR contributed to the conception and design of the study, data collection, analysis and interpretation of data, and the process of writing and revising the manuscript, and with the overall responsibility for the project in which the study is included. All three authors approved the submission of the manuscript in its present form.

Financial support. This work was supported by FORTE: Swedish Research Council for Health, Working Life and Welfare (2014-04980; 2016-07089); Kamprad Family Foundation, and Strategic Research Area Health Care Science $(\mathrm{SFO}-\mathrm{V})$. $^{*}$

Conflict of interest. The authors declare no conflicts of interest.

Ethical standards. Ethical approval for this study was obtained from the Stockholm Ethical Committee (2015/512-31/5).

\section{References}

Andrews GJ, Evans J and Wiles JL (2013) Re-spacing and re-placing gerontology: relationality and affect. Ageing \& Society 33, 1339-1373.

Artner L (2018) Materialities in and of institutional care for elderly people. Frontiers of Sociology 3, 30.

Atkinson P, Delamont S and Housley W (2008) Contours of Culture. Complex Ethnography and the Ethnography of Complexity. Plymouth, UK: AltaMira Press.

Calkins MP (2009) Evidence-based long term care design. Neurorehabilitation 25, 145-154.

Calkins MP (2018) From research to application: supportive and therapeutic environments for people living with dementia. The Gerontologist 58, 114-128.

Chaudhury H, Cooke HA, Cowie H and Razaghi L (2018) The influence of the physical environment on residents with dementia in long-term care settings: a review of the empirical literature. The Gerontologist 58, 325-337.

Cutchin MP (2003) The process of mediated aging-in-place: a theoretically and empirically based model. Social Science and Medicine 57, 1077-1090.

Cutchin MP, Owen SV and Chang PF (2003) Becoming 'at home' in assisted living residences: exploring place integration processes. Journals of Gerontology: Psychological Sciences and Social Sciences 58B, 234-243.

Day K, Carreon D and Stump C (2000) The therapeutic design of environments for people with dementia: a review of the empirical research. The Gerontologist 40, 397-416.

de Boer B, Beerens HC, Katterbach MA, Viduka M, Willemse BM and Verbeek H (2018) The physical environment of nursing homes for people with dementia: traditional nursing homes, small-scale living facilities, and green care farms. Healthcare 6, 137.

Degnen C (2016) Socialising place attachment: place, social memory and embodied affordances. Ageing \& Society 36, 1645-1667.

Desjarlais RR (2003) Sensory Biographies: Lives and Death Among Nepal's Yolmo Buddhists. Berkeley, CA: University of California Press.

Digby R and Bloomer MJ (2014) People with dementia and the hospital environment: the view of patients and family carers. International Journal of Older People Nursing 9, 34-43.

Downey G (2005) Learning Capoeira. Lessons in Cunning from an Afro-Brazilian Art. Oxford: Oxford University Press.

Falk H, Wijk H, Persson LO and Falk K (2013) A sense of home in residential care. Scandinavian Journal of Caring Sciences 27, 999-1009.

\footnotetext{
${ }^{*}$ This article was originally published without a statement regarding the financial support given by the Kamprad Family Foundation. This has now been corrected and a corrigendum published at https://doi.org/ $10.1017 /$ S0144686X20001403.
} 
Fay R and Owen C (2012) 'Home' in the aged care institution: authentic or ersatz. Procedia - Social and Behavioral Sciences 35, 33-43.

Fleming R, Goodenough B, Low LF, Chenoweth L and Brodaty H (2016) The relationship between the quality of the built environment and the quality of life of people with dementia in residential care. Dementia - International Journal of Social Research and Practice 15, 663-680.

Gesler WM and Kearnes RA (2002) Culture/Place/Health. London: Routledge.

Gilleard C, Hyde M and Higgs $\mathbf{P}$ (2007) The impact of age, place, aging in place, and attachment to place on the well-being of the over 50s in England. Research on Aging 29, 590-605.

Goffman E (1990) Asylums: Essays on the Social Situation of Mental Patients and Other Inmates. New York, NY: Doubleday.

Gustavsson A (2000) Tolkning och tolkningsteori 1. Introduktion [Interpretation and Interpretation Theory 1. Introduction]. Stockholm: Pedagogiska Institutionen, Stockholms Universitet. (In Swedish)

Hillcoat-Nallétamby S and Ogg J (2014) Moving beyond 'ageing in place': older people's dislikes about their home and neighbourhood environments as a motive for wishing to move. Ageing \& Society 34, 1771-1796.

Huot S and Rudman DL (2010) The performance and places of identity: conceptualizing intersections of occupation, identity, and place in the process of migration. Journal of Occupational Science 17, 68-77.

Ingold T (2008) Anthropology is not ethnography (Radcliff-Brown Lecture in Social Anthropology). Proceedings of the British Academy 154, 69-92.

Johansson K, Laliberte Rudman D, Mondaca M, Park M, Luborsky M, Josephsson S and Asaba E (2013) Moving beyond 'aging in place' to understand migration and aging: place making and the centrality of occupation. Journal of Occupational Science 20, 108-119.

Kenkmann A, Poland F, Burns D, Hyde P and Killett A (2017) Negotiating and valuing spaces: the discourse of space and 'home' in care homes. Health \& Place 43, 8-16.

Killett A, Burns D, Kelly F, Brooker D, Bowes A, La Fontaine J, Latham I, Wilson M and O'Neill M (2016) Digging deep: how organisational culture affects care home residents' experiences. Ageing \& Society 36, 160-188.

Klaassens M and Meijering L (2015) Experiences of home and institution in a secured nursing home ward in the Netherlands: a participatory intervention study. Journal of Aging Studies 34, 92-102.

Lee SY, Chaudhury H and Hung L (2016) Effects of physical environment on health and behaviors of residents with dementia in long-term care facilities: a longitudinal study. Research in Gerontological Nursing 9, 81-91.

Marquardt G, Bueter K and Motzek T (2014) Impact of the design of the built environment on people with dementia: an evidence-based review. HERD 8, 127-157.

Mondaca M, Josephsson S, Katz A and Rosenberg L (2018) Influencing everyday activities in a nursing home setting: a call for ethical and responsive engagement. Nursing Inquiry 25, e12217.

Mondaca M, Josephsson S, Borell L, Katz A and Rosenberg L (2019) Altering the boundaries of everyday life in a nursing home context. Scandinavian Journal of Occupational Therapy 26, 441-451.

Moore KD and Ekerdt DJ (2011) Age and the cultivation of place. Journal of Aging Studies 25, 189-192.

Nakrem S, Vinsnes AG, Harkless GE, Paulsen B and Seim A (2013) Ambiguities: residents' experience of 'nursing home as my home'. International Journal of Older People Nursing 8, 2016-2025.

National Board of Health and Welfare (2017) Nationella riktlinjer för vård och omsorg vid demenssjukdom [National Guidelines for the Care of Persons with a Dementia Disease]. Available at https:/www.socialstyrelsen. se/regler-och-riktlinjer/nationella-riktlinjer/slutliga-riktlinjer/demens/.

National Board of Health and Welfare (2019a) Vård och omsorg om äldre. Lägesrapport 2019 [Health and Social Care of Older People. The Situation 2019]. Available at https://www.socialstyrelsen.se/globalassets/ sharepoint-dokument/artikelkatalog/ovrigt/2019-3-18.pdf.

National Board of Health and Welfare (2019b) Statistik om socialtjänstinsatser till äldre 2018 [Statistics About Social Care for Older People 2018]. Available at https://www.socialstyrelsen.se/globalassets/sharepoint-dokument/artikelkatalog/statistik/2019-5-7.pdf.

Okely J (1994) Vicarious and sensory knowledge of chronology and change: ageing in rural France. In Hastrup K and Hervik P (eds). Social Experience and Anthropological Knowledge. London: Routledge, pp. 47-61.

Parker C, Barnes S, McKee K, Morgan K, Torrington J and Tregenza P (2004) Quality of life and building design in residential and nursing homes for older people. Ageing \& Society 24, 941-962. 
Peace S, Holland C and Kellaher L (2005) The influence of neighborhood and community on well-being and identity in later life: an English perspective. In Rowles GD and Chaudhury H (eds). Home and Identity in Late Life: International Perspectives. New York, NY: Springer, pp. 297-316.

Penney L (2013) The uncertain bodies and spaces of aging in place. Anthropology and Aging Quarterly 34, $113-125$.

Pink S (2009) Doing Sensory Ethnography. London: Sage.

Pucillo F and Cascini G (2014) A framework for user experience, needs and affordances. Design Studies 35, 160-179.

Ricoeur P (1991) From Text to Action. Evanston, IL: Northwestern University Press.

Rijnaard MD, van Hoof J, Janssen BM, Verbeek H, Pocornie W, Eijkelenboom A, Beerens HC, Molony SL and Wouters EJ (2016) The factors influencing the sense of home in nursing homes: a systematic review from the perspective of residents. Journal of Aging Research 2016, 6143645.

Robinson CA, Reid RC and Cooke HA (2010) A home away from home: the meaning of home according to families of residents with dementia. Dementia 9, 490-508.

Rosenberg L and Johansson K (2012) Where the transactions happen: the unit of analysis when applying a transactional perspective. In Cutchin MC and Dickie VA (eds). Transactional Perspectives on Occupation. New York, NY: Springer, pp. 147-156.

Rowles GD (1991) Beyond performance: being in place as a component of occupational therapy. American Journal of Occupational Therapy 5, 265-271.

Rowles GD and Chaudhury H (eds) (2005) Home and Identity in Late Life: International Perspectives. New York, NY: Springer.

Rowles GD, Oswald F and Hunter EG (2003) Interior living environments in old age. In Wahl H-W, Scheidt RJ and Windley PG (eds). Annual Review of Gerontology and Geriatrics. Focus on Aging in Context: Socio-Physical Environment. New York, NY: Springer, pp. 167-194.

Seamon D (1979) A Geography of the Lifeworld: Movement, Rest and Encounter. New York, NY: St. Martin's Press.

Shield RR, Looze J, Tyler D, Lepore M and Miller SC (2014) Why and how do nursing homes implement culture change practices? Insights from qualitative interviews in a mixed methods study. Journal of Applied Gerontology 33, 737-763.

Torrington J (2009) The design of technology and environments to support enjoyable activity for people with dementia. ALTER, European Journal of Disability Research 3, 123-137.

van Hoof J, Rutten PGS, Struck C, Huisman ERCM and Kort HSM (2015) The integrated and evidence-based design of healthcare environments. Architectural Engineering and Design Management 11, 243-263.

Van't Leven $\mathbf{N}$ and Jonsson $\mathbf{H}$ (2002) Doing and being in the atmosphere of the doing: environmental influences on occupational performance in a nursing home. Scandinavian Journal of Occupational Therapy 9, 148-155.

Wiles JL, Leibing A, Guberman N, Reeve J and Allen RES (2012) The meaning of 'aging in place' to older people. The Gerontologist 52, 3357-3366.

Cite this article: Johansson K, Borell L, Rosenberg L (2022). Qualities of the environment that support a sense of home and belonging in nursing homes for older people. Ageing \& Society 42, 157-178. https:// doi.org/10.1017/S0144686X20000896 